\title{
Teknik Mekanika Tubuh Mengurangi Tingkat Nyeri Punggung Bawah pada Ibu Hamil Trimester III
}

\author{
Nur Azizah Putri Rahayu ${ }^{1}$, Rafika $^{2}$, Lili Suryani ${ }^{1}$, Hadriani $^{1}$ \\ ${ }^{1} J u r u s a n$ Kebidanan Poltekkes Kemenkes Palu \\ ${ }^{2}$ Poltekkes Kemenkes Makassar \\ *Email korespondensi: rafikauddinramli@gmail.com
}

\begin{abstract}
Article Info
ABSTRACT

Article history:

In order to reduce and prevent back pain complaints and to form

Submitted: 2020-06-04

Accepted: 2020-08-16

Published: 2020-08-30

safe and comfortable daily activities during pregnancy, pregnant women need proper body mechanics. The purpose of this research is to know the influence of the application of mechanical body mechanics with lower back pain of the III trimester of pregnant Keywords:

Mechanical body mechanics; Lower back pain; Pregnant; women. This type of research is pre-experimental with one group Pretest posttest design. This research was conducted in the working area of Puskesmas Sangurara. The population in this study is all IIItrimester pregnant mothers with a sample number of 31 people, taken with a consecutive sampling technique. The treatment given is the technique of body mechanics observed during 1 week. Data collection using an observation sheet. The results showed before performing mechanical body mechanics there were $71 \%$ of respondents experienced moderate pain and after conducting mechanical body mechanics there were $74.2 \%$ of respondents experienced mild pain. Based on the Wilcoxon test obtained a pvalue $<0.001$, with an average decrease in pain, is 7.50 . The conclusion is the application of body mechanics techniques significantly affect the lower back pain of the III trimester of pregnant women.
\end{abstract}

Kata kunci:

Mekanika tubuh; nyeri punggung bawah; ibu hamil;

\section{ABSTRAK}

Untuk mengurangi dan mencegah keluhan nyeri punggung dan membentuk aktivitas sehari-hari yang aman dan nyaman selama kehamilan maka ibu hamil perlu mekanika tubuh yang benar. Penelitian ini bertujuan melihat pengaruh teknik mekanika tubuh mengurangi tingkat nyeri punggung bawah pada ibu hamil trimester III. Penelitian ini adalah pra eksperimen dengan desain one group pretest posttest. Penelitian ini dilakukan di wilayah kerja Puskesmas Sangurara. Populasi dan sampel yaitu seluruh ibu hamil trimester III berjumlah 31 orang dengan teknik consecutive sampling. Analisis data univariat dan uji Wilcoxon. Perlakuan yang diberikan berupa teknik mekanika tubuh yang diobservasi selama 1 minggu. Numeric Rating Scale (NRS) digunakan untuk penilaian nyeri. Hasil penelitian menunjukkan sebelum melakukan teknik mekanika tubuh terdapat $71 \%$ responden yang mengalami nyeri sedang dan setelah melakukan teknik mekanika tubuh terdapat $74,2 \%$ responden mengalami nyeri ringan. Analisis statistik menunjukkan $p$-value 0,000 , dengan rata-rata penurunan nyeri adalah 7,50. Kesimpulan yaitu teknik mekanika tubuh berpengaruh secara signifikan mengurangi tingkat nyeri punggung bawah pada ibu hamil trimester III 


\section{PENDAHULUAN}

Setiap wanita yang memiliki organ reproduksi sehat, apabila telah mengalami menstruasi dan melakukan hubungan seksual dengan seorang pria yang organ reproduksinya sehat, sehingga besar kemungkinan terjadi kehamilan. ${ }^{1}$ Masa kehamilan dimulai dari konsepsi sampai lahirnya janin berlangsung selama 280 hari (40 minggu atau 9 bulan 10 hari) dihitung dari hari pertama haid terakhir. ${ }^{2}$ Selama hamil seorang ibu mengalami perubahan-perubahan yang terjadi baik fisik maupun psikologi. Perubahan tersebut menyebabkan ibu hamil mengalami ketidaknyamanan. Rasa tidak nyaman yang dirasakan oleh ibu hamil biasanya berbeda-beda setiap trimester kehamilan. ${ }^{3}$

Kehamilan dibagi menjadi tiga triwulan, triwulan I dimulai dari konsepsi sampai 12 minggu, triwulan II dari 12 sampai 28 minggu dan trimester III dari 28 sampai 40 minggu. ${ }^{4}$ Ketidaknyamanan yang dirasakan oleh ibu hamil trimester III, yaitu berat badan ibu meningkat drastis sehingga membuat ibu cepat lelah, sukar tidur, nafas pendek, kaki dan tangan oedema, rasa nyeri pada punggung, varises, dan kram pada kaki. ${ }^{5}$ Salah satu keluhan kehamilan trimester III seringkali mengalami nyeri punggung bawah. Hal ini biasa disebabkan karena perubahan horman, sehingga jaringan lunak penyangga dan penghubung mengalami penurunan elastisitas dan fleksibilitas otot. ${ }^{6}$

Beberapa faktor yang dapat mempengaruhi timbulkan keluhan nyeri punggung selama kehamilan diantaranya perubahan postur tubuh, berat badan bertambah dan redistribusiligamen, tulang punggung bawah dan bagu melengkung ke depan sehingga terjadi peregangan otot abdomen yang lemah sehingga ada kecenderungan otot punggung untuk memendek apabila otot abdomen meregang mengakibatkan ketidakseimbangan otot sekitar pelvis dan kaku dapat dirasakan di atas ligamen. Hal ini berakibat rasa nyeri punggung dari sakroiliaka atau lumbal menimbulkan gangguan punggung jangka panjang. Selain itu aktivitas fisik selama kehamilan. ${ }^{7}$

Faktor lain yang biasa berisiko timbul peningkatan rasa nyeri punggung karena pada wanita sebelumnya telah memiliki riwayat kelainan sakit punggung dan ditambah berat badan berlebih. ${ }^{7}$ Nyeri punggung dapat mengakibatkan aktivitas setiap hari ibu terganggu, sehingga membutuhkan bantuan orang lain apabila ingin bergerak. ${ }^{8}$ Keluhan nyeri punggung pada ibu apabila tidak diatasi dapat mengakibatkan keluhan rasa nyeri punggung jangka panjang. Jika nyeri punggung pascapartum dan nyeri punggung kronik selama kehamilan mengalami peningkatan menyebabkan akan lebih sulit untuk diobati atau disembuhkan. ${ }^{9}$

Berbagai upaya untuk mengatasi nyeri, baik secara farmakologi maupun alternatif. Metode alternatif dapat dilakukan melalui kegiatan tanpa pemberian obat diantaranya mandi air hangat, kompres panas atau dingin, latihan nafas dalam, terapi musik, aromaterapi, relaksasi, massage, dan perubahan posisi tubuh serta senam yoga. ${ }^{10,11}$ Mekanika tubuh ibu hamil yang benar dalam beraktivitas setiap hari dapat menurunkan keluhan nyeri punggung, sehingga kondisi tubuh ibu yang aman dan nyaman selama masa kehamilan. Mekanika tubuh pada ibu hamil merupakan posisi tubuh yang benar menyesuaikan perubahan tubuh pada ibu dengan membetulkan tulang punggung bentuk lordosis. Mekanika tubuh ibu hamil seperti posisi berdiri dan duduk yang benar, posisi sewaktu bangun tidur, gerakan mengangkat beban dan menjongkok. ${ }^{8}$ Mekanika tubuh yang dilakukan dengan benar tidak memiliki efek samping pada ibu maupun janin, serta mudah dan tidak membutuhkan biaya yang mahal. Adapun manfaat yang lain terdiri dari tubuh ibu 
rileks, mengontrol berat badan, tonus otot menjadi baik, mengatasi stress, relaksasi dan memperlancar peredaran darah menuju otot dan organ tubuh yang lain agar terjadi peningkatan kelenturan tubuh. ${ }^{12}$

Tarsika dan Silfiana (2017) menyatakan bahwa intensitas nyeri punggung responden sebelum diberikan perlakuan paling banyak yaitu $67 \%$ berada pada nyeri sedang dengan skala 4-6, intensitas nyeri responden setelah diberi perlakuan paling banyak yaitu $72 \%$ berada pada nyeri ringan dengan skala $1-3$, terjadi penurunan nyeri sebesar $78 \%$ dari keseluruhan responden sehingga teknik mekanika tubuh dapat mempengaruhi intensitas nyeri punggung pada kehamilan. ${ }^{13}$ Hasil penelitian Dewi (2017) bahwa ibu hamil trimester memiliki body mekanik baik sebesar 58,3\% responden dan kurang baik $41,7 \%$. Ibu nyeri punggung sebesar $45,8 \%$ dan tidak mengalami nyeri punggung $54,2 \%{ }^{8}$

Data di Indonesia menunjukkan jumlah ibu yang hamil tahun 2016 sebesar 5.355.710 jiwa dan di Sulawasi Tengah sebanyak 69.548 jiwa. ${ }^{14}$ Data Dinas Kesehatan Kota Palu 2017 menyebutkan jumlah ibu hamil di Kota Palu sebanyak 7.569 orang di Puskesmas Sangurara sebesar 1.020 orang. Begitu pula data Puskesmas Sangurara tahun 2017 menyebutkan bahwa jumlah ibu hamil trimester III sebanyak 157 orang. ${ }^{15}$

Hasil wawancara dengan 3 ibu hamil trimester III di wilayah kerja Puskesmas Sangurara pada saat kelas ibu hamil di Posyandu Dahlia, ditemukan bahwa 3 ibu hamil mengatakan mengalami keluhan nyeri punggung. Dalam mengatasi kondisi tersebut dapat dilakukan beberapa cara metode alternatif mengurangi keluhan ibu tersebut seperti gerakan berbaring, massage punggung atas bawah. Hal ini mendasari dalam melakukan penelitian mengenai teknik mekanika tubuh mengurangi nyeri punggung bawah pada ibu hamil trimester III.

\section{METODE PENELITIAN}

Penelitian ini adalah pra eksperimen dengan desain one group pretest posttest. Desain dengan mengukur skala nyeri awal sebelum diberikan perlakuan dan mengukur skala nyeri setelah diberikan perlakuan teknik mekanika tubuh yang benar. Penelitian ini dilaksanakan pada Mei sampai Juni 2018 di wilayah Puskesmas Sangurara. Populasi penelitian adalah seluruh ibu trimester III berjumlah 104 orang di wilayah Puskesmas Sangurara dengan jumlah sampel sebanyak 31 sampel yang diperoleh menggunakan rumus Slovin. ${ }^{16}$ Metode pengambilan sampel menggunakan teknik consecutive sampling sesuai kriteria inklusi sampel terdiri dari lbu yang merasakan nyeri punggung bawah dan bersedia menjadi responden. Sedangkan kriteria ekslusi ibu yang mengalami penyakit kelainan tulang belakang. Pengumpulan data penelitian dilakukan selama \pm 1 bulan.

Sebelum melakukan penelitian pada responden, peneliti menjelaskan intervensi yang akan dilakukan dan peneliti melakukan anamnesa terkait data identitas responden. Peneliti menanyakan intensitas nyeri dengan menggunakan cek list Numeric Rating Scale (NRS) yang dialami responden sebelum dilakukan tindakan teknik mekanika tubuh, kemudian peneliti menjelaskan, memberi contoh dan mengajarkan teknik mekanika tubuh. Peneliti mengarahkan responden untuk melakukan teknik mekanika tubuh yang telah diajarkan selama 1 minggu, pada hari ke-7 peneliti mengkaji intensitas nyeri yang dirasakan responden setelah melakukan teknik mekanika tubuh dan data yang diperoleh didokumentasikan. Analisis data secara univariat dengan penentuan nilai distribusi frekuensi. Analisis bivariat menggunakan uji Wilcoxon. 


\section{HASIL PENELITIAN}

Berdasarkan hasil pengolahan data maka dapat disajikan analisis data yaitu sebagai berikut:

Untuk melihat gambaran distribusi responden berdasarkan umur, usia kehamilan, pendidikan dan pekerjaan maka dapat dilihat pada tabel berikut ini:

Tabel 1. Karakteristik Responden di Wilayah Kerja Puskesmas Sangurara

\begin{tabular}{lrr}
\hline \multicolumn{1}{c}{ Karakteristik } & Frekuensi & Presentase \\
\hline Umur & 3 & \\
$<20$ & 26 & 9,7 \\
$20-35$ & 2 & 83,9 \\
$>35$ & & 6,5 \\
Usia Kehamilan & 6 & 19,4 \\
$28-31$ Minggu & 20 & 64,5 \\
$32-35$ Minggu & 5 & 16,1 \\
$36-37$ Minggu & 3 & \\
Pendidikan & 24 & 9,7 \\
SMP & 4 & 77,4 \\
SMA & & 12,9 \\
Perguruan Tinggi & 22 & 74,2 \\
Pekerjaan & 2 & 6,5 \\
IRT & 4 & 12,9 \\
Wiraswasta & 3 & 9,7 \\
Honorer & & \\
Pedagang & & \\
\hline
\end{tabular}

Sumber: Data primer, 2018

Tabel 1 diketahui lebih banyak umur 20-35 tahun sebesar 26 orang $(83,9 \%)$, dan responden terbanyak dengan usia kehamilan 32-35 minggu yaitu sebanyak 20 orang $(64,5)$ dengan tingkat pendidikan responden terbanyak adalah berpendidikan SMA yaitu 24 orang $(77,4 \%)$. Pekerjaan responden yang paling banyak adalah IRT yaitu 22 orang $(74,2 \%)$.

Tabel 2. Perubahan tingkat Nyeri Sebelum dan Sesudah Teknik Mekanika Tubuh

\begin{tabular}{lrrrr}
\hline \multirow{2}{*}{ Skala Nyeri } & \multicolumn{2}{c}{ Sebelum } & \multicolumn{2}{c}{ Sesudah } \\
\cline { 2 - 5 } & $\mathbf{n}$ & $\%$ & $\mathbf{n}$ & $\%$ \\
\hline Nyeri ringan (1-3) & 9 & 29,0 & 23 & 74,2 \\
Nyeri sedang (4-6) & 22 & 71,0 & 8 & 25,8 \\
\hline
\end{tabular}

Sumber: Data primer, 2018

Tabel 2 diketahui bahwa sebelum melakukan teknik mekanika tubuh responden mengalami nyeri terbanyak pada skala 4-6 dengan kategori nyeri sedang. Sedangkan, setelah melakukan teknik mekanika tubuh responden mengalami nyeri terbanyak pada skala 1-3 dengan kategori nyeri ringan 
Tabel 3. Pengaruh teknik mekanika tubuh dalam mengurangi nyeri punggung bawah ibu hamil trimester III

\begin{tabular}{lcccc}
\hline $\begin{array}{c}\text { Nyeri punggung } \\
\text { bawah }\end{array}$ & $\mathbf{N}$ & $\begin{array}{c}\text { Mean } \\
\text { (Min-max) }\end{array}$ & $\begin{array}{c}\text { Mean } \\
\text { rank }\end{array}$ & p value \\
\hline Pretest & 31 & $\begin{array}{c}1,71(1-2) \\
1,26(1-2)\end{array}$ & 7,50 & $<0,001$ \\
Posttest & & & & \\
\hline
\end{tabular}

Sumber: Data primer, 2018

Tabel 3 menunjukkan jumlah responden sebanyak 31 orang. Hasil analisis statistik bahwa ibu hamil mengalami penurunan (pengurangan) nyeri dari nilai rerata pretest yaitu 1,71 dan nilai rerata posttest yaitu 1,26. Analisis uji Wilcoxon diperoleh $p$-value<0,001, dapat disimpulkan mekanika tubuh berpengaruh mengurangi nyeri punggung bawah pada ibu hamil trimester III.

\section{PEMBAHASAN}

Hasil pada 31 responden diperoleh mayoritas responden berusia 20-35 tahun. Hal ini merupakan usia seseorang masih mudah menerima informasi karena berkaitan daya ingat terhadap informasi yang diterima, oleh karena itu ibu akan memiliki pengetahuan cukup khususnya pengetahuan tentang pentingnya melakukan teknik mekanika tubuh yang benar selama kehamilan.

Mayoritas pendidikan responden berupa pendidikan SMA merupakan pendidikan menengah, seseorang memiliki pemikiran yang mulai matang dan mampu mengaplikasikan informasi yang diterima. ${ }^{17}$ Pendidikan merupakan salah satu faktor yang menentukan pengetahuan dan persepsi seseorang terhadap pentingnya suatu hal, termasuk pentingnya penerapan teknik mekanika tubuh yang benar selama kehamilan.

Mayoritas pekerjaan responden yaitu Ibu Rumah Tangga (IRT). Keletihan dan kelelahan seseorang akan meningkatkan sensasi nyeri. Pekerjaan ibu sebagai IRT juga dapat meningkatkan resiko nyeri punggung. ${ }^{18}$ Fraser (2009) mengemukakan nyeri punggung pada ibu dapat dipicu oleh aktivitas selama kehamilan, sejumlah tugas rumah tangga yang dilakukan dalam posisi duduk, berdiri dalam waktu yang lama, mengangkat barang berat, dengan seluruh gerakan berputar sambil mengangkat merupakan gerakan yang beresiko dilakukan ibu hamil. ${ }^{19}$ Penelitian ini dilakukan kepada ibu hamil yang telah memasuki trimester III karena sesuai dengan penjelasan Fraser (2009) bahwa faktor predisposisi nyeri punggung salah satunya mempengaruhi pertumbuhan uterus selama perkembangan kehamilan menyebabkan teregangnya ligamen penopang biasanya menimbulkan spasme otot berupa nyeri. ${ }^{19}$

Hasil penelitian ini menunjukkan mekanika tubuh yang paling sering benar dilakukan oleh ibu hamil yaitu berdiri, duduk dan bangun. Sedangkan, mekanika tubuh yang paling sering tidak benar dilakukan oleh ibu hamil yaitu ketika mengangkat benda yang ada dilantai dan berbaring. Hasil penelitian bahwa ibu yang telah melakukan mekanika tubuh selama kehamilan secara benar seperti ketika posisi duduk, berdiri, mengangkat barang yang ada dilantai, berbaring dan bangun mengalami penurunan nyeri punggung.

Responden yang telah melakukan teknik mekanika tubuh dari mengalami nyeri sedang menjadi nyeri ringan. Tarsikah dan Silfiana (2017) yang menyatakan bahwa nyeri berkurang karena adanya perbaikan postur pada ibu hamil. ${ }^{13}$ Mekanika tubuh melibatkan penggunaan tubuh secara efesien untuk mendistribusikan berat badan 
dan tekanan yang sama rata diantara beberapa kelompok otot. Menurut Reeder (2008), postur tubuh yang baik adalah berdiri, duduk, berjalan dan berbaring merupakan gerakan meminimalkan rongga atau lengkungan punggung bawah. Teknik dalam mekanika tubuh ini menggunakan 3 prinsip dasar yang sangat berperan yaitu gravitasi, keseimbangan dan berat benda. ${ }^{20}$ Hidayat (2009) menyatakan bahwa faktor penting dalam prinsip gravitasi yaitu pusat gravitasi, garis gravitasi serta dasar tumpuan. ${ }^{21}$ Dasar tumpuan yang luas dan kesejajaran tubuh yang baik akan menghemat penggunaan energi dan mencegah kelelahan otot. ${ }^{22}$

Menurut Reeder (2008), selama melaksanakan aktivitas sehari-hari, seperti mengerjakan pekerjaan rumah, berjalan, dan menaiki tangga, ibu hamil sebaiknya mempertahankan punggung agar tetap berada dalam kesejajaran yang tepat. Upaya dalam kesejajaran ini diharapkan energi yang dikeluarkan lebih sedikit, sehingga manfaat dari mekanika tubuh dapat dirasakan lebih optimal tidak hanya dapat mengurangi nyeri punggung namun lebih luas yaitu bermanfaat bagi janin, diantaranya sirkulasi darah dari ibu ke janin lebih lancar. ${ }^{20}$ Melakukan teknik mekanika tubuh yang baik dapat menstabilkan tonus otot dan postur tubuh, menjaga berat badan, mengatasi stress, meningkatkan relaksasi dan memperlancar peredaran darah menuju otot dan organ tubuh yang lain. ${ }^{12}$ Hasil penelitian ini sejalan dengan penelitian yang dilakukan Dewi (2017) menyatakan bahwa sebagian besar ibu hamil trimester III mempunyai gerakan tubuh yang baik, tidak merasakan nyeri punggung bawah. ${ }^{8}$

Salah satu faktor ketidaknyaman pada ibu hamil yaitu nyeri punggung, yang intensitasnya meningkat sejalan dengan bertambahnya usia kehamilan. Hasil penelitian ini menunjukkan ibu mengalami nyeri punggung bawah dengan kisaran nyeri sedang lebih banyak sebelum perlakukan, setelah dilakukan teknik mekanika tubuh yang baik terjadi penurunan menjadi nyeri ringan yang lebih banyak. Kebanyakan nyeri punggung dikaitkan dengan masalah mekanika tubuh yang tidak benar. Dalam kehamilan, posisi gerakan tubuh dengan benar ketika berdiri, duduk, mengangkat barang berat, berbaring dan bangun mengalami penurunan nyeri punggung. Menurut Thorn (2003) bahwa gerakan cara duduk, berdiri, berjalan, berbaring, membungkuk dan mengangkat dengan baik merupakan metode prinsip mekanika tubuh yang perlu diperhatikan agar menghindari nyeri punggung. ${ }^{23}$ Varney (2007) menambahkan cara mengatasi nyeri punggung membenarkan posisi tubuh dan penggunakan mekanika tubuh yang tepat saat beraktivitas. ${ }^{2}$

Ummah (2012) bahwa mekanika tubuh berhubungan dengan kejadian nyeri punggung pada kehamilan. Mekanika tubuh yang baik akan menurunkan kejadian nyeri punggung. ${ }^{7}$ Hawes menyatakan responden dengan teknik mekanika tubuh dengan benar saat posisi berdiri, duduk, mengangkat benda yang dilantai, berbaring dan bangun tidak akan mengalami nyeri punggung. Namun, responden yang melakukan mekanika tubuh dengan benar ada yang mengalami nyeri punggung dan ada yang tidak mengalami nyeri punggung, ini dapat diakibatkan oleh faktor lain selain mekanika tubuh. ${ }^{24}$

Teknik mekanika tubuh diharapkan dapat mengatasi ketidaknyamanan nyeri punggung bawah pada ibu selama kehamilan. Sebagaimana yang dijelaskan oleh Varney (2007) bahwa mekanika tubuh yang tepat dapat mengatasi nyeri punggung. Sesuai dengan hasil penelitian ini bahwa teknik mekanika tubuh mengurangi nyeri punggung bawah pada ibu hamil trimester III dari nyeri sedang menjadi nyeri ringan. Oleh karena itu, penerapan teknik mekanika tubuh dapat dijadikan sebagai salah satu upaya dalam mengatasi nyeri punggung bawah pada ibu hamil trimester III. ${ }^{2}$ 


\section{SIMPULAN DAN SARAN}

Kesimpulkan bahwa penerapan teknik mekanika tubuh berpengaruh secara signifikan dalam menurunkan tingkat nyeri punggung bawah pada ibu hamil trimester III. Saran diantaranya 1). pihak Puskesmas dan pustu serta fasilitas kesehatan lainnya diharapkan dapat memberikan konseling dan mengajarkan tentang teknik mekanika tubuh kepada ibu hamil sehingga dapat membantu dalam menangani permasalahan nyeri punggung, 2). Perlu peneliti selanjutnya dapat melakukan penelitian dengan melakukan observasi secara berkala dan membandingkan antara berbagai macam teknik untuk mengurangi nyeri punggung bawah ibu hamil.

\section{UCAPAN TERIMA KASIH}

Penulis mengucapkan terima kasih kepada Kepala Puskesmas Sangurara yang telah memberikan izin meneliti dan seluruh responden yang telah berpartisipasi sehingga penelitian ini dapat dilaksanakan dengan sangat baik.

\section{DAFTAR PUSTAKA}

1. Mandriawati GA, Anriani NW, Harini RT, Darmapatni MWG, Javani S. Asuhan Kebidanan Kehamilan Berbasis Kompetensi. 3rd ed. Jakarta: EGC; 2016.

2. Varney H. Buku Ajar Asuhan Kebidanan. 4th ed. Jakarta: EGC; 2007.

3. Emilta DA, Andayani A, Astuti FP. Perbedaan Intensitas Nyeri Punggung Bawah Ibu Hamil Trimester III Sebelum dan Sesudah Pemberian Terapi Kombinasi Teknik Acupressure dan Aromaterapi Lavender. Pros Semin Nas Kebidanan Dan Present Has Ris. 2017;

4. Marmi. Asuhan Kebidanan pada Masa Antenatal. Yogyakarta: Pustaka Belajar; 2014.

5. Mediarti D, Sulaiman, Rosnani, Jawiah. Pengaruh Yoga Antenatal Terhadap Pengurangan Keluhan Ibu Hamil Trimester III. J Kedokt dan Kesehat. 2014;1(1):4753.

6. Wahyuni, Prabowo E. Manfaat Kinesiotapping untuk Mengurangi Nyeri Punggung Bawah pada Kehamilan Trimester III. J Kesehat Masy. 2012;5(2).

7. Ummah F. Nyeri Punggung pada Ibu Hamil ditinjau dari Body Mekanik dan Paritas di Desa Ketanen Kecamatan Panceng Kabupaten Gresik. 2012;3(13).

8. Dewi HK. Hubungan Mekanika Tubuh (Body Mekanik) dengan Nyeri Punggung pada Ibu Hamil Trimester III di Wilayah Kerja Puskesmas Kambangan Lebaksiu Kabupaten Tegal. Pros Semin Nas Kebidanan dan Call Pap. 2017;

9. Fatmawati FF. Upaya Penurunan Rasa Nyaman pada Ibu Hamil Trimester III dengan Nyeri Punggung. Fakultas IImu Kesehatan Universitas Muhammadiyah Surakarta; 2017.

10. Nurtiyana E. Upaya Penanganan Nyeri Pinggang pada lbu Hamil Trimester ke-III di Puskesmas Grogot Sukoharjo. Universitas Muhamadiyah Sukoharjo; 2016.

11. Pont AV, Rosiyana NM, Pratiwi V, Enggar, Nurfatimah, Ramadhan K. The Effect of Prenatal Yoga in Reducing Pregnancy Complaints. Indian J Public Heal Res Dev [Internet]. 2019;10(8):1218. Available from: http://www.indianjournals.com/ijor.aspx?target=ijor:ijphrd\&volume=10\&issue=8\&article $=223$

12. Asmadi. Teknik Prosedural Keperawatan, Konsep, dan Aplikasi Kebutuhan Dasar Klien. Jakarta: Salemba Medika; 2008.

13. Tarsikah, Silfiana E. Penerapan Teknik Mekanika Tubuh untuk Mengurangi Nyeri Punggung pada Ibu Hamil Trimester II dan III. Matern Neonatal Heal J. 2017;1(1):4-9.

14. Kementerian Kesehatan R.I. Profil Kesehatan Indonesia Tahun 2016 in: Kesehatan Keluarga. Jakarta: Kementerian Kesehatan R.I.; 2017.

15. Dinas Kesehatan Kota Palu. Profil Kesehatan Kota Palu. Palu: Dinas Kesehatan Kota Palu; 2017. 
16. Nursalam. Metodologi Penelitian Ilmu Keperawatan. Jakarta: Salemba Medika; 2017.

17. Notoatmodjo S. Pendidikan dan Perilaku Kesehatan. Jakarta: Rineka Cipta; 2003.

18. Prasetyo SN. Konsep dan Proses Keperawatan Nyeri. Yogyakarta: Graha IImu; 2010.

19. Fraser DM, Cooper MA, Fletcher G. Buku Ajar Bidan Myles. Jakarta: EGC; 2009.

20. Reeder SJ. Maternity Nursing: Family, Newborn, and Women's Health Care. Jakarta: EGC; 2008.

21. Hidayat AA. Pengantar Kebutuhan Dasar Manusia. Jakarta: Salemba Medika; 2009.

22. Mubarak WI, Chayanti N. Buku Ajar Kebutuhan Dasar Manusia: Teori dan Aplikasi dalam Praktik. Jakarta: EGC; 2007.

23. Thorn G. Kehamilan Sehat: Panduan Praktis Diet, Olahraga, dan Relaksasi bagi Ibu Hamil. Jakarta: Erlangga; 2003.

24. Hawes AF. Nyeri Punggung dan Mekanika Tubuh pada Ibu Hamil. Fakultas Keperawatan Universitas Sumatera Utara; 2015. 